\title{
Effects of long-term treatment with resveratrol and subcutaneous and oral estradiol administration on pituitary function in rats
}

\author{
Martina Böttner*, Julie Christoffel ${ }^{* 1}$, Hubertus Jarry ${ }^{1}$ \\ and Wolfgang Wuttke ${ }^{1}$ \\ Department of Anatomy, University of Lübeck, Ratzeburger Allee 160, D-23538 Lübeck, Germany \\ ${ }^{1}$ Department of Clinical and Experimental Endocrinology, University of Göttingen, 37075 Göttingen, Germany \\ (Requests for offprints should be addressed to M Böttner; Email: boettner@anat.uni-luebeck.de) \\ *(M Böttner and J Christoffel contributed equally to this work)
}

\begin{abstract}
Hormone replacement therapy (HRT) has been used for several decades to treat menopausal discomforts. However, in the light of recent studies that draw attention to the potential hazards of conventional HRT, various attempts have been undertaken to search for alternatives to classical HRT. Phytoestrogens are claimed to be capable of positively influencing menopausal symptoms, including hot flushes. We designed a long-term study of 3 months to assess the effects of subcutaneous and orally fed $17 \beta-$ estradiol (E2), as well as the actions of resveratrol (RES) on pituitary function in female rats. Our results have demonstrated that RES binds with a 10-fold lower affinity to estrogen receptor (ER)- $\alpha$ than to ER $\beta$. The data from the in vivo study revealed that a dosage of $5 \mu \mathrm{g}$ and $50 \mu \mathrm{g}$ $\mathrm{RES} / \mathrm{kg}$ bodyweight per day given to ovariectomized (OVX)
\end{abstract}

rats achieved serum levels of $1 \cdot 0$ and $8 \cdot 1 \mu \mathrm{M}$ respectively. Long-term treatment of OVX rats with RES revealed no estrogenic potential on pituitary function in vivo as assessed by $\mathrm{LH}$ and prolactin secretion and by regulation of mRNAs for LH $\alpha$, LH $\beta$, and GnRH receptor. Subcutaneous treatment with E2 in silastic capsules exerted stronger effects on $\mathrm{LH}$ and prolactin secretion, as well as on LH $\beta, \mathrm{LH} \alpha, \mathrm{GnRH}$ receptor, and ER $\beta$ mRNA regulation compared with orally applied estradiol benzoate despite comparable serum levels. Levels of aryl hydrocarbon receptor (AhR) mRNA in the pituitary were increased following OVX and attenuated by longterm E2 treatment, whereas RES did not modulate AhR mRNA expression.

Journal of Endocrinology (2006) 189, 77-88

\section{Introduction}

Estrogens, especially $17 \beta$-estradiol (E2), are pleiotropic gonadal steroids that affect many physiological functions including reproduction, bone metabolism, the cardiovascular system, and brain function. Menopause marks the end of the reproductive life span of women and is characterized by a dramatic drop in circulating estrogen. Symptoms associated with estrogen deprivation include vasomotor instability (hot flushes), genitourinary atrophy, osteoporosis, and depression. Hormone replacement therapy (HRT) has been successfully used to treat the symptoms of menopause because estrogen has stong suppressive effects on climacteric complaints. Recent studies, however, have uncovered a greater understanding of the hazards of HRT. The Women's Health Initiative Study was abandoned because several adverse effects including higher risk for breast cancer and coronary heart disease outweighed the benefits of hormone treatment for postmenopausal women (Burger 2003, Derry 2004). Similar results were obtained from the more recent
'Million Women Study' (Beral 2003). These findings led to various attempts to search for alternatives to classical HRT.

Epidemiological studies reveal that Asian women have a lower incidence of menopausal discomforts, uterine and breast cancer, and cardiovascular disease compared with Western populations (Bagchi et al. 2001); this might be due to the ingestion of higher amounts of phytoestrogens. Phytoestrogens are claimed to be capable of positively influencing menopausal symptoms and increasing bone density (Anderson \& Garner 1998, Chiechi 1999, Chiechi et al. 1999, Ramsey et al. 1999). One representative of these compounds is trans-3,5,4-trihydroxystilbene (resveratrol; RES), a member of the stilbene group that is produced in many plants such as grape vines, berries, and peanuts. A growing body of evidence suggests that RES ameliorates postmenopausal symptoms including hot flushes, bone strength, mood swings, and brain function. It may also prevent many of the adverse side-effects observed after regular HRT (Bagchi et al. 2001). RES has been shown to exhibit anti-carcinogenic properties (ElAttar \& Virji 1999, Bhat et al. 2001), to act as an 
anti-inflammatory agent (Bhat \& Pezzuto 2002, Donnelly et al. 2004), and to have anti-oxidant potential (Cadenas \& Barja 1999, Lin \& Tsai 1999). Furthermore, RES has been shown to exhibit estrogenic activity in vitro (Gehm et al. 1997, Ashby et al. 1999, Bowers et al. 2000). The in vivo actions of RES, however, remain to be investigated.

Overactivation of phasic and synchronous activity of the pulse generator and overspilling hypothalamic neurotransmitters stimulating gonadotropin-releasing hormone $(\mathrm{GnRH})$ neurons have been associated with hot flushes (Ravnikar 1990). Treatment of ovariectomized (OVX) women or rats with E2 dampens the activity of the $\mathrm{GnRH}$ pulse generator, resulting in reduced pituitary luteinizing hormone $(\mathrm{LH})$ secretion and diminishing or ceasing hot flushes. Thus, the negative feedback action of E2 or substances with estrogenic activity on LH secretion can be used as an indirect measure of the potency to ameliorate hot flush activity (Seidlova-Wuttke et al. 2003b).

As we are facing the problem of searching for safe treatments of menopausal discomforts we designed the current long-term study to investigate the influence of two ways of treatment with E2 and administration of RES on pituitary function. We therefore implemented a paradigm of subcutaneous constant E2 treatment that is thought to mimic delivery of E2 via patches and a paradigm of orally fed estradiol benzoate (E2B) that was designed to resemble taking E2 via a pill. RES was fed to OVX rats to assess the putative estrogenic actions of the phytoestrogen. Animals were treated for 3 months to mimic for the human situation where women are on HRT for a long period of time.

From short-term studies it is known that treatment of OVX animals with estrogen leads to suppression of LH secretion due to negative feedback on the pituitary and on hypothalamic centers that control GnRH release (Caraty et al. 1989, Shupnik 1996). In contrast, prolactin levels are suppressed upon OVX and rise after treatment with E2 (Raymond et al. 1978). It is furthermore known that, following OVX, LH $\alpha$, LH $\beta$, GnRH receptor, and estrogen receptors (ERs) are modulated (Gharib et al. 1986, Papavasiliou et al. 1986, Shupnik 1996). These experiments, however, were conducted under short-term OVX or E2 replacement conditions. We used these parameters in our models of transdermal and oral E2 administration to assess whether the route of E2 delivery or treatment with RES might affect pituitary function in our long-term paradigm of hormone replacement.

The aryl hydrocarbon receptor (AhR) was initially identified by Poland et al. (1979) and shares only weak sequence homology with steroid receptors. Later the protein became known as the mediator of the toxic and anti-estrogenic effects of dioxin. Since the AhR is able to bind RES (Casper et al. 1999) and to negatively interact with ER signaling (Safe \& Wormke 2003) we determined AhR expression patterns following OVX and treatment with E2 and RES.

\section{Materials and Methods}

\section{Chemicals}

17ß-E2-3-benzoate (purity 98.5\%) and 17 $\beta$-E2 (purity 98\%) were purchased from Sigma. RES (purity 99.2\%) was obtained from Nabio Biotechnology, Shanghai, China.

\section{Animals}

All experiments were conducted according to the German animal welfare regulations under permission nos $509 \cdot 42502 / 01-36 \cdot 03$ and 509.42502/01-28.04, district authorities Braunschweig. The procedures conform with FRAME guidelines.

Parental female Sprague-Dawley rats were obtained from Fa. Winkelmann (Borchen, Germany) and given soy-free food. Offspring were raised under soy-free conditions to eliminate exposure to exogenous estrogenic compounds. Animals were kept under standard conditions: water and food ad libitum, lights on from 0600 to $1800 \mathrm{~h}$, room temperature $23{ }^{\circ} \mathrm{C}$, and relative humidity $55 \%$. At the age of 4 months, rats were bilaterally OVX under isofluorane anesthesia.

\section{Animal diet and batches of test compound}

The chow was provided by Ssniff special diets $\mathrm{GmbH}$ (Soest, Germany). Regular diet was the soy-free formulation Ssniff SM R/M, $10 \mathrm{~mm}$. The supplemented chow was prepared by mixing the test substances with this formulation to homogeneity before the process of pelleting. Concentrations in $1 \mathrm{~kg}$ food were: E2B low 0.0043 g and E2B high 0.0173 g, RES low 0.084 g, RES high $0.84 \mathrm{~g}$. All batches were prepared 1 week prior to the start of the experiment.

\section{Hormone treatment and drug delivery}

To assess the effects of constant exposure to E2 versus a cycling pattern of hormone delivery we implemented two experimental set-ups. The first group of animals received silastic capsules that were filled with $17 \beta-E 2$ in sesame oil $(1 \mathrm{mg} / \mathrm{ml})$ or sesame oil as a vehicle. Capsules were implanted subcutaneously $(n=11-12$ animals/ experimental group; one capsule/animal). This treatment paradigm produces constant exposure and blood levels of E2 that are equivalent to circulating hormone levels during the rat estrous cycle (Dubal et al. 1998). To ensure exposure to constant E2 levels during the whole experiment, capsules were changed three times. Agematched intact rats served as controls. The second group of animals was fed with two doses of E2B. The low dose of E2B (E2B-l) consisted of $4.3 \mathrm{mg} / \mathrm{kg}$ food, the high dose (E2B-h) of $17 \cdot 3 \mathrm{mg} / \mathrm{kg}$ food. OVX animals served as 
controls ( $n=9-12 /$ experimental group). All animals were compared with the intact random cycling animals. To assess the effect of long-term exposure to RES, OVX animals were fed with two doses of the phytoestrogen. The low dose consisted of $0.084 \mathrm{~g}$ RES $/ \mathrm{kg}$ food, the high dose of $0.84 \mathrm{~g} / \mathrm{kg}$ food. OVX rats served as the respective control group. After 3 months of treatment, animals were decapitated under $\mathrm{CO}_{2}$ anesthesia. In order to minimize inter-individual variations due to circadian fluctuations of hormones, blood samples were obtained between 0800 and $1200 \mathrm{~h}$.

\section{HPLC analysis}

To recover the substances from serum in detectable amounts for HPLC-u.v., enzymatic hydrolysis of potential metabolites was performed before serum extraction. Five hundred microliters of serum were diluted with $500 \mu \mathrm{l}$ ammonium acetate buffer $(\mathrm{pH} 5 \cdot 0)$ containing $1 \mathrm{mg}$ $\beta$-glucuronidase (Helix pomatia $\beta$-glucuronidase Type H1; Sigma) and incubated overnight at $37^{\circ} \mathrm{C}$. Samples were prepared by the Strata X solid phase extraction method according to the manufacturer's guidelines and eluted with ethanol. The eluted volume was evaporated to dryness in a speedvac with 4-methyl-umbelliferone (4MU) serving as an internal standard for the following reconstitution. Samples were reconstituted with $100 \mu$ l ethanol. Subsequently, samples were filtered through a PVDF membrane $(0 \cdot 45 \mu \mathrm{m} / 4 \mathrm{~mm})$ filter to remove remaining protein pollutants. An injection volume of $20 \mu \mathrm{l}$ was chromatographed over an NC $250 \times 4.6 \mathrm{~mm}$ Hypersil-ODS 5.0 $\mu \mathrm{m}$ column (Bischoff, Leonberg, Germany). Serum spikes of 4MU, 4MU-glucuronide (4MUG), and 4MU-sulfate (4MUS) were included in each preparation as duplicate controls and detected by the fluorescence of free $4 \mathrm{MU}$ (RF-10A XL fluorescence detector; Shimadzu, Duisburg, Germany): 4MUG and 4MUS served as controls of hydrolysis with $4 \mathrm{MU}$ being their reference as well as control of extraction in comparison with the internal standard. Serum spikes with RES were analyzed versus samples dissolved in ethanol. The standard curve was obtained from spikes of pooled serum, treated exactly as the regular unknowns as described above.

Ethanol, acetonitril, and water were obtained from $\mathrm{J} \mathrm{T}$ Baker (Phillipsburg, NJ, USA); o-phosphoric acid 85\% p.a. was supplied by Merck. The respective extracts were eluted at a flow rate of $1 \mathrm{ml} / \mathrm{min}$ with a linear binary gradient of water containing $0 \cdot 085 \%$ o-phosphoric acid (A) and acetonitrile (B): $t=0 \mathrm{~min}: \mathrm{A} 70 \%, t=15 \mathrm{~min}: \mathrm{A}$ 25\%, $t=16-21 \mathrm{~min}:$ A $0 \%, t=22-29 \mathrm{~min}$ A $70 \%$. The signal was detected with a u.v./visible spectrophotometer (LC-95; Perkin-Elmer, Fremont, CA, USA) at $305 \mathrm{~nm}$.

\section{Hormone analysis}

The blood samples were centrifuged $(3000 \mathrm{~g}, 20 \mathrm{~min})$ and the serum was stored at $-20{ }^{\circ} \mathrm{C}$ for further analysis.
LH and prolactin were measured by a specific RIA supplied by the National Hormone and Pituitary Program of the NIH as described previously (Roth et al. 2001). E2 levels were assessed using a kit (E2 third generation; DSL, Sinsheim, Germany) according to the manufacturer's guidelines. The specific activity of ${ }^{125}$ iodine-E2 was $81 \cdot 4$ TBq mmol (2200 Ci/mmol); 40000 c.p.m. $/ 100 \mu \mathrm{l}$ tracer were used in the assay.

\section{Tissue preparation}

Pituitaries were removed, frozen in liquid nitrogen, and stored at $-70{ }^{\circ} \mathrm{C}$ until used. Trunk blood was collected and stored at $4^{\circ} \mathrm{C}$ for $2-6 \mathrm{~h}$. Samples were centrifuged at $3000 \mathrm{~g}$ for $10 \mathrm{~min}$ and serum was stored at $-20^{\circ} \mathrm{C}$ until analysis.

\section{$R N A$ extraction and reverse transcription}

Extraction of total RNA from pituitaries was performed using a RNeasy mini kit (Quiagen) according to the manufacturer's guidelines. Reverse transcription was carried out in a total volume of $20 \mu$ containing $1 \times$ reaction

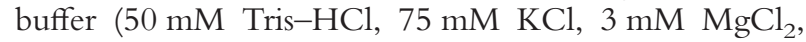
$50 \mathrm{mM}$ dithiothreitol), $100 \mathrm{ng}$ random hexamer primer, $0.5 \mathrm{mM}$ dNTPs, $200 \mathrm{U}$ M-MMLV reverse transcriptase RNase $\mathrm{H}^{-}$(Promega), $4 \mathrm{U}$ RNasin (Promega), and $200 \mathrm{ng}$ total RNA. Samples were incubated for $10 \mathrm{~min}$ at $22{ }^{\circ} \mathrm{C}$ to allow primer annealing, reverse transcription was at $42{ }^{\circ} \mathrm{C}$ for $50 \mathrm{~min}$, and finally RNA-cDNA hybrids were denatured for $10 \mathrm{~min}$ at $95^{\circ} \mathrm{C}$.

\section{Real-time PCR}

Real-time PCR reactions were based on the $5^{\prime}$-nuclease assay (Heid et al. 1996) which was run on an ABI Prism 7700 sequence detection system (TaqMan; PE Applied Biosystems, Foster City, CA, USA). Primers and probes were designed with the Primer Express software (PE Applied Biosystems, Weiterstadt, Germany) and purchased from Eurogentec (Seraing, Belgium). The hybridization probe is linked at the $5^{\prime}$-end to 6-carboxyfluorescein (FAM) as fluorogenic reporter dye and at the $3^{\prime}$-end to the fluorogenic group 6-carboxy-tetramethylrhodamine (TAMRA) which quenches the FAM emission spectrum. Primers and probes for ER $\alpha, E R \beta$, and $\mathrm{GnRH}$ receptor were described previously (Roth et al. 2001, Seidlova-Wuttke et al. 2003a,b), the PCR for AhR was carried out according to Lovekamp-Swan et al. (2003). Oligonucleotides, accession numbers (AC), and references for LH $\beta$ and $\alpha$-subunit are listed below.

LH- $\beta$ : forward primer: $5^{\prime}$-ACCTTCACCACCAGCA TCTGT-3'; reverse primer: 5'-AGCTCACGGTAGGT GCACACT-3', TaqMan hybridization probe: 5'-FAMCTGCCTTGCCTCCCGTGCCTCA-TAMRA-3' (AC: NM 012858 (Chin et al. 1983)); $\alpha$-subunit: forward primer: 5'-TCTTGGACCTTGCGGGAGT-3', reverse 
primer: 5'-GGTGCCCCCATCTATCAGTG-3'; TaqMan hybridization probe: 5'-FAM-TGCCCTGGAGAA GCAACAGCCCAT-TAMRA-3' (AC: V01252 (Godine et al. 1982)).

Amplification reactions were carried out in a $25 \mu \mathrm{l}$ volume containing $1 \times$ TaqMan Universal PCR Master Mix (PE Applied Biosystems), 50-900 nM primers, $225 \mathrm{nM}$ hybridization probe, and $2 \mu \mathrm{l}$ cDNA. Subsequently, samples were amplified over 40 cycles. Each cycle consisted of a denaturation phase of $15 \mathrm{~s}$ at $95^{\circ} \mathrm{C}$ and a hybridization/elongation phase of $1 \mathrm{~min}$ at $60{ }^{\circ} \mathrm{C}$.

\section{ER ligand-binding assays}

In addition, subtype-specific ER $\alpha$ and ER $\beta$ ligandbinding assays were performed according to the method described by Kuiper et al. (1997) with the exception that bound and free tracer were separated by absorption on dextran-coated charcoal as described previously (SeidlovaWuttke et al. 2003a). The tracer for the ligand-binding assay was ${ }^{125}$ I-labeled E2 (NEN, Dreieich, Germany). The recombinant $\operatorname{ER} \alpha$ and $\operatorname{ER} \beta$ proteins were obtained from PanVera (Madison, WI, USA).

\section{Statistical analysis}

Significant differences between the control and treatment groups were analyzed by one-way ANOVA followed by Newman-Keuls post-hoc test (PrismTM; GraphPad, San Diego, CA, USA). $P$ values $<0 \cdot 05$ were considered significant.

Relative changes of mRNA levels were analyzed in the PCR experiments. For evaluation of the effect of OVX and E2 treatment, the mean value of the absolute data measured in the group of intact animals was set as $100 \%$. All other values determined in the respective assay are expressed in relation to the average value of intact animals. For the assessment of the estrogenic potential of RES, the treatment groups were assayed in relation to the OVX control group that was set as $100 \%$.

\section{Results}

Since a prerequisite for a given substance to act as an estrogen agonist is binding to the respective receptors we first determined the binding of RES to recombinant ER $\alpha$ and ER $\beta$ (Fig. 1). Non-labeled E2 displaced the radioactively labeled ligand from $\mathrm{ER} \alpha$ with an $\mathrm{IC}_{50}$ value of $11 \cdot 24 \mathrm{nM}$ (Fig. 1A). RES bound only weakly to ER $\alpha$ with an $\mathrm{IC}_{50}$ of $14.61 \mu \mathrm{M}$. Thus, RES bound to ER $\alpha$ with a 1300-fold lower affinity than E2. With regard to $\mathrm{ER} \beta$, E2 bound with an $\mathrm{IC}_{50}$ value of $1.958 \mathrm{nM}$ (Fig. $1 \mathrm{~B})$. RES displaced $\mathrm{E} 2$ from $\mathrm{ER} \beta$ with an $\mathrm{IC}_{50}$ of $4.82 \mu \mathrm{M}$, demonstrating that the binding affinity for RES to bind to ER $\beta$ is 2500 -fold lower than for E2.
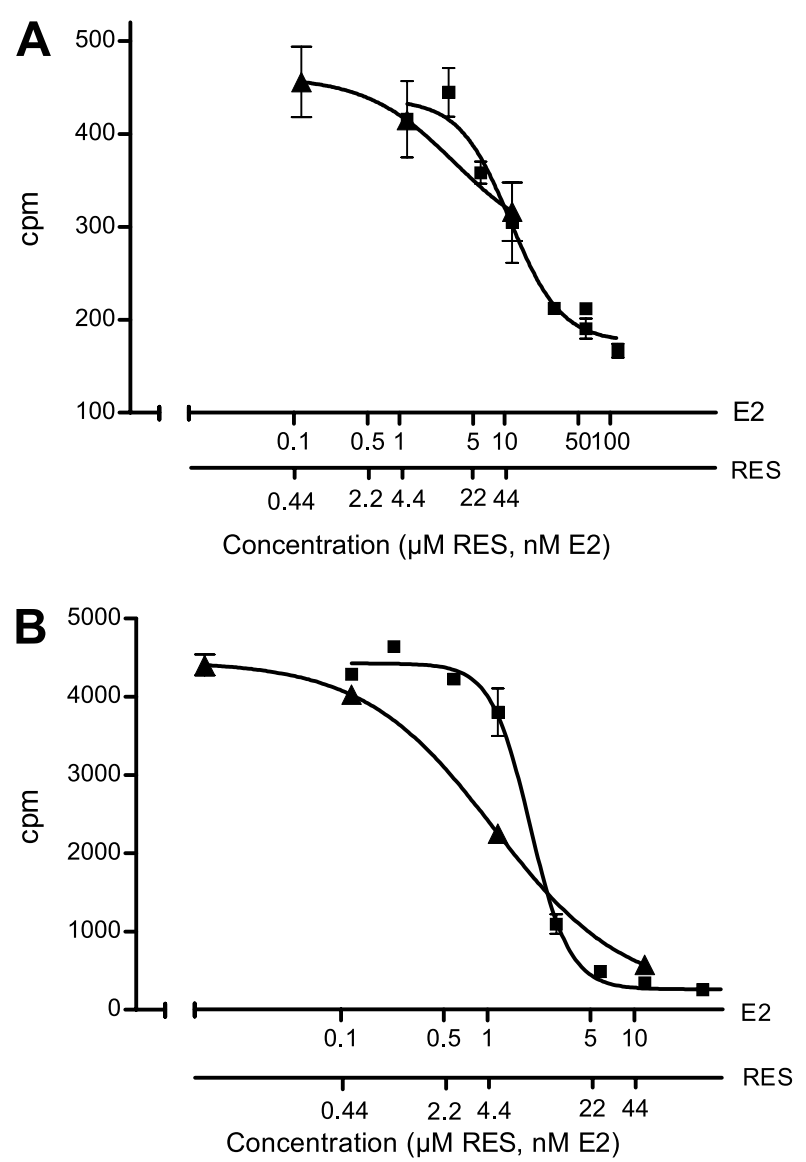

Figure 1 RES competes for ER binding. ER-binding assays were performed using recombinant ER $\alpha$ (A) or ER $\beta$ (B). Radiolabeled E2 competed with the indicated concentrations of RES $(\boldsymbol{\Delta})$ or unlabeled E2 ( $\mathbf{\square})$. The graphs show one representative out of three experiments. Values are means \pm S.E.M.

We next determined serum E2 and RES levels in our animals (Table 1). Intact rats exhibited an average of $19.9 \mathrm{pg} / \mathrm{ml} \mathrm{E} 2$. Levels dropped upon OVX to $8 \cdot 3$ or

Table 1 Serum levels of E2 and RES

\begin{tabular}{lr} 
& \multicolumn{2}{c}{ E2 } \\
\cline { 2 - 2 } $\begin{array}{l}\text { Treatment group } \\
\text { Intact }\end{array}$ \\
Oil & $19 \cdot 9( \pm 2 \cdot 2) \mathrm{pg} / \mathrm{ml}$ \\
OVX & $8 \cdot 3( \pm 3 \cdot 4) \mathrm{pg} / \mathrm{ml}$ \\
E2 (s.c.) & $9 \cdot 5( \pm 1 \cdot 9) \mathrm{pg} / \mathrm{ml}$ \\
E2B-I (oral) & $26 \cdot 2( \pm 3 \cdot 5) \mathrm{pg} / \mathrm{ml}$ \\
E2B-h (oral) & $40 \cdot 3( \pm 16 \cdot 7) \mathrm{pg} / \mathrm{ml}$ \\
& $153 \cdot 2( \pm 49 \cdot 6) \mathrm{pg} / \mathrm{ml}$
\end{tabular}

RES low

RES high

$238 \cdot 3 \mathrm{ng} / \mathrm{ml}(1 \cdot 044 \mu \mathrm{M})$ $1 \cdot 854 \mathrm{ng} / \mathrm{ml}(8 \cdot 125 \mu \mathrm{M})$

E2 levels were measured by RIA, RES contents were assessed by HPLC. Data are shown as means \pm S.E.M., $n=9-12$. Since the study was part of a multi-organic risk assessment, some of these data were also used in an aging study (Böttner 2005). 
$9 \cdot 5 \mathrm{pg} / \mathrm{ml}$ respectively. Implantation of silastic capsules gave rise to E2 levels of $26 \mathrm{pg} / \mathrm{ml}$ which represent values that occur in cycling animals. Animals fed with the low dose of E2 were characterized by $40 \mathrm{pg} / \mathrm{ml} \mathrm{E} 2$ which lay well within the physiological range of cycling animals. In contrast, the high dose of orally fed E2B gave rise to serum levels of $153 \mathrm{pg} / \mathrm{ml}$ which represents a pharmacological dose. After digest with a Helix pomatia extract and HPLC analysis we measured $238 \mathrm{ng} / \mathrm{ml}(1 \cdot 0 \mu \mathrm{M})$ RES in the group of animals that was treated with the low dose and $1.85 \mu \mathrm{g} / \mathrm{ml}(8 \cdot 1 \mu \mathrm{M})$ RES in animals that were fed with the high dose of the phytoestrogen.

To investigate the effects of long-term treatment with E2 or RES on pituitary function we first assessed serum hormone profiles. LH levels rose 25-fold upon OVX (Fig. 2). Constant exposure to E2 led to a suppression of LH similar to the situation in intact animals (Fig. 2A). In contrast, the low dose of orally fed E2 only partially suppressed OVX-induced LH secretion (Fig. 2B). In this case we observed reduction by $35 \%$. The high dose of E2B led to a 90\% reduction in LH levels; however, serum levels were still twice as high as in animals bearing silastic capsules. Treatment of OVX rats with RES had no significant effect on $\mathrm{LH}$ values (Fig. 2C).

Compared with intact rats, levels of prolactin decreased to $28 \%$ and to $19 \%$ in both OVX groups (Fig. 3). Constant exposure to E2 led to an increase of serum prolactin to $155 \mathrm{ng} / \mathrm{ml}$ (Fig. 3A). In contrast, orally fed E2 was only able to partially reverse the OVX-induced decrease (Fig. 3B). Animals treated with the low dose of E2 exhibited prolactin concentrations of $19 \mathrm{pg} / \mathrm{ml}$, those fed with the high dose showed serum levels of $53 \mathrm{ng} / \mathrm{ml}$, neither of which differed significantly from values obtained in OVX animals. RES did not cause any alterations in prolactin levels compared with OVX rats (Fig. 3C).

To assess whether changes in secretion patterns were paralleled by changes in transcription profiles we determined LH mRNA expression in the pituitary. Upon OVX we observed a 15 -fold increase in LH $\beta$ subunit mRNA expression compared with intact animals (Fig. 4). Constant E2 exposure led to suppression of LH $\beta$ to the levels found in cycling animals. This effect was only achieved by the pharmacological dose of $\mathrm{E} 2 \mathrm{~B}$ whereas the physiological dose led only to a partial decrease in LH $\beta$ mRNA expression, thus reflecting the changes in $\mathrm{LH}$ secretion patterns described above. RES showed no reduction of OVX-induced LH $\beta$ mRNA levels.

Expression profiles for $\mathrm{LH} \alpha$ mRNA mirrored the expression of LH $\beta$ mRNA. In OVX rats we observed a 5 -fold increase of LH $\alpha$ mRNA expression that was attenuated in the presence of constant physiological levels of E2 (Fig. 5). Orally administered E2 decreased $\alpha$-subunit mRNA levels dose dependently whereas treatment of OVX rats with RES did not affect transcription.

We next examined GnRH receptor mRNA contents in our long-term treatment model and after RES exposure.
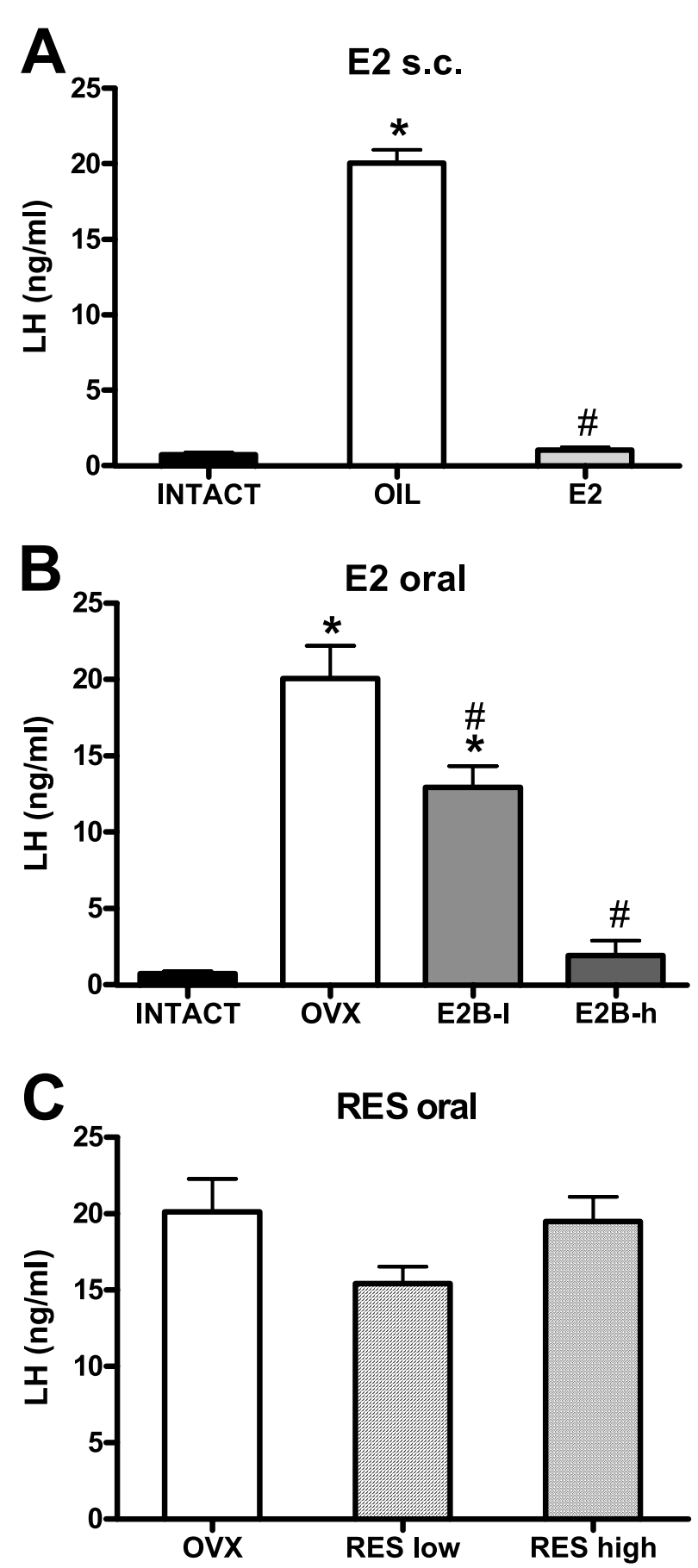

Figure 2 Serum levels of LH. LH levels were measured by RIA. (A) OVX, oil-treated animals showed elevated LH levels that were decreased by subcutaneous E2 treatment. (B) OVX-induced LH concentrations were dose dependently decreased by orally fed E2B. (C) Orally fed RES did not modulate LH levels. Data are shown as means \pm S.E.M., $n=9-12$. ${ }^{*} P<0.05$ vs intact; $\# P<0 \cdot 05$ vs OIL/OVX. 

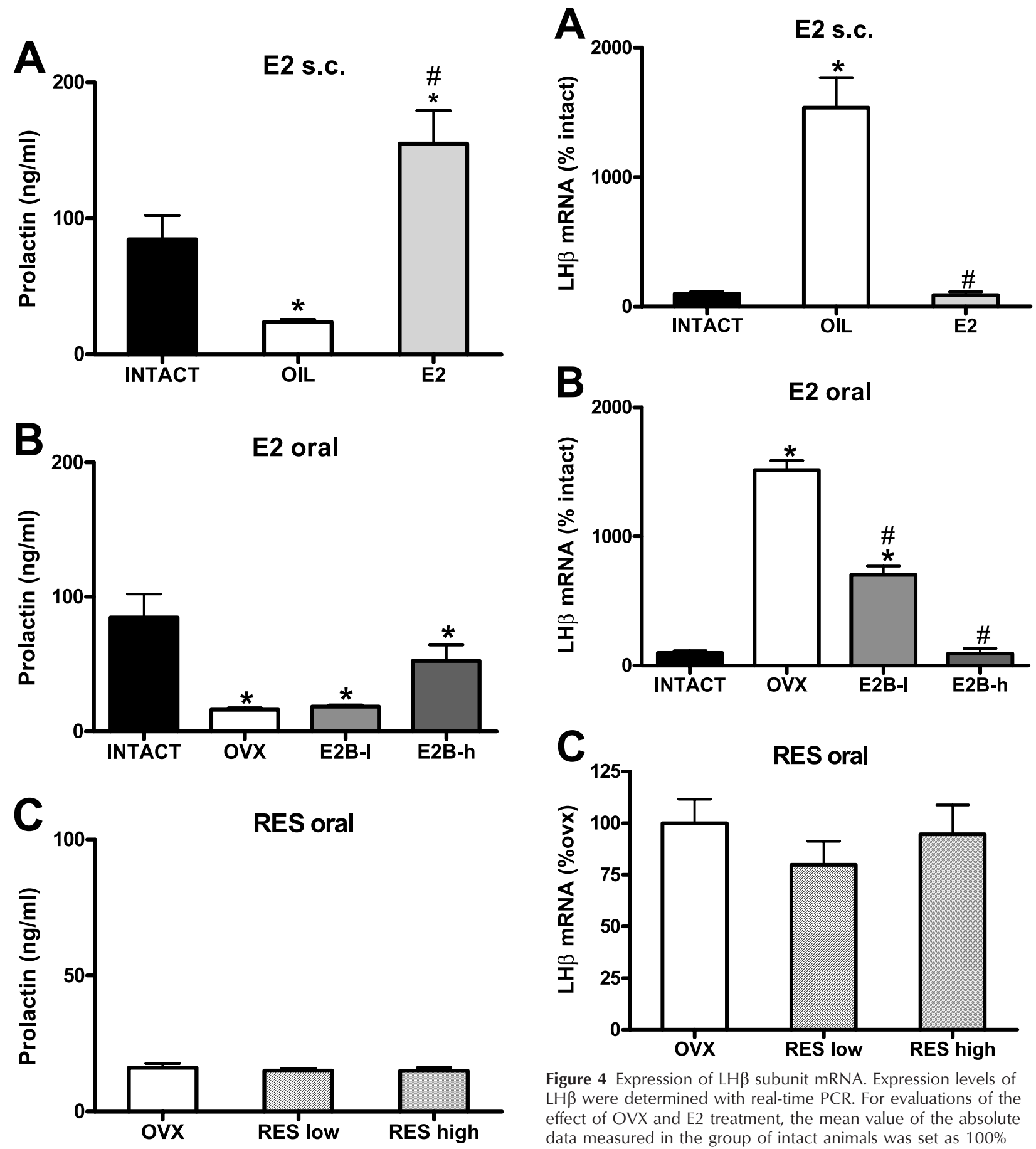

Figure 4 Expression of LH $\beta$ subunit mRNA. Expression levels of $\mathrm{LH} \beta$ were determined with real-time PCR. For evaluations of the effect of OVX and E2 treatment, the mean value of the absolute data measured in the group of intact animals was set as $100 \%$ $(\mathrm{A}$ and $\mathrm{B})$. All other values determined in the respective experiment are expressed in relation to the average value of intact animals. (A) Oil-treated, OVX animals showed elevated LH- $\beta$ mRNA levels that were suppressed after subcutaneous E2 treatment. (B) The OVX-induced rise in LH $\beta$ mRNA was dose-dependently attenuated by orally fed E2B. For the assessment of the estrogenic potential of RES, the treatment groups were assayed in relation to the OVX control group that was set as $100 \%$. (C) Orally fed RES did not influence LH $\beta$ mRNA levels. Data are represented as means \pm S.E.M., $n=9-12 .{ }^{\star} P<0 \cdot 05$ vs intact; $\# P<0 \cdot 05$ vs OIL/OVX. 

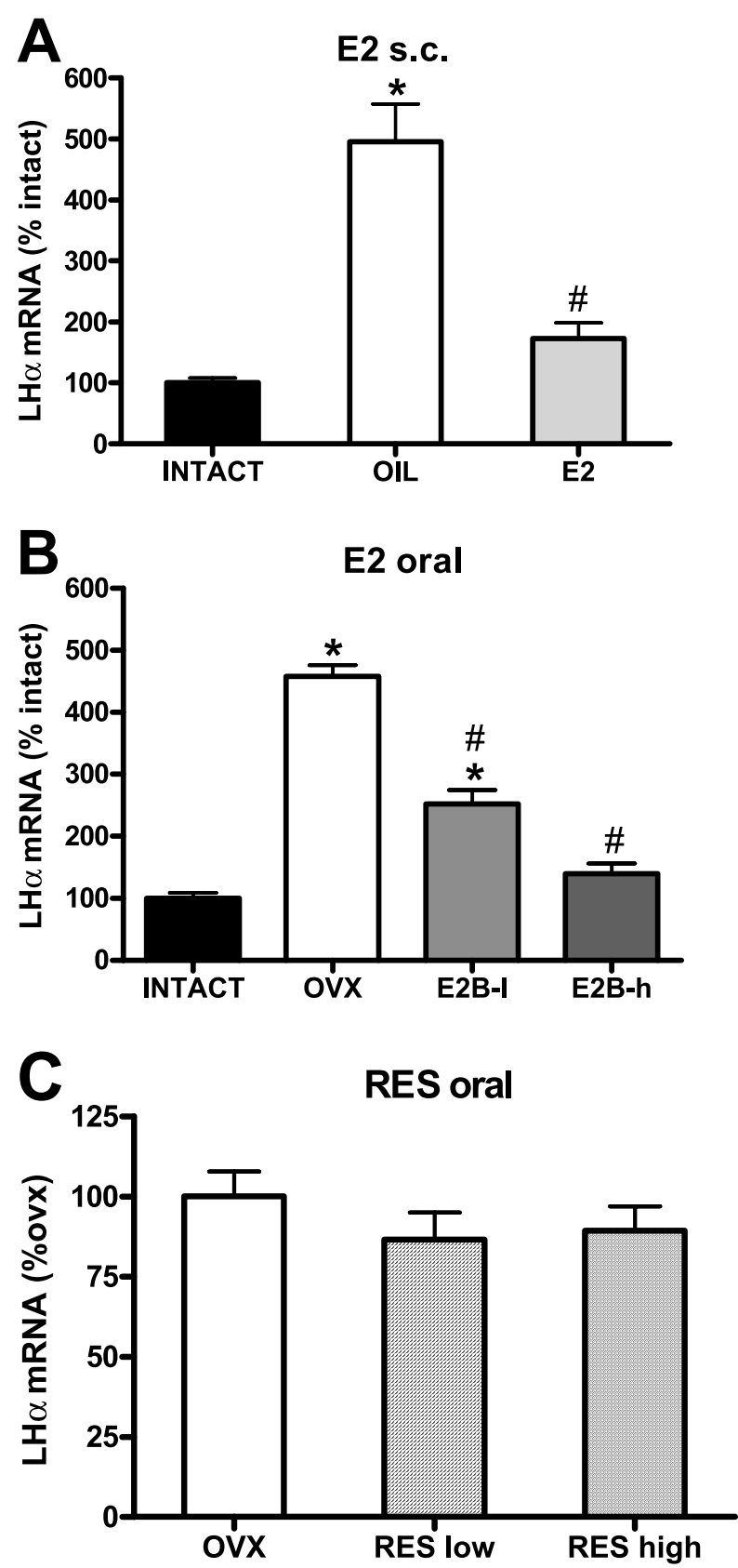

Figure 5 Expression of $\mathrm{LH} \alpha$ subunit mRNA. Levels for OVX and E2-treated animals are expressed as a percentage of intact animals (A and B). (A) LH $\alpha$ mRNA levels were strongly induced after OVX in vehicle-treated rats. Subcutaneous E2 treatment led to a decrease in LH $\alpha$ mRNA concentrations. (B) Orally applied E2B dose-dependently attenuated the OVX-induced increase in $\mathrm{LH} \alpha$ mRNA concentrations. (C) RES-treated animals are shown in relation to the OVX control group. Orally fed RES did not affect LH $\alpha$ mRNA levels. Data are represented as means \pm S.E.M., $n=9-12 .{ }^{*} P<0.05$ vs intact; $\# P<0.05$ vs OIL/OVX. Since some of these data are also part of an aging study the data in Fig. 5A are also used in that aging study (Böttner \& Wuttke 2005).
The results for $\mathrm{GnRH}$ receptor mRNA mimicked the expression profile of LH $\beta$ mRNA expression. OVX induced GnRH receptor mRNA 7-fold compared with naive females (Fig. 6). Subcutaneously administered E2 reduced GnRH receptor mRNA expression to levels similar to those observed in intact rats. This effect could only be mimicked by the high dose of orally fed E2; the low dose, however, led only to a partial reduction of GnRH receptor mRNA expression. As demonstrated for the regulation of $\mathrm{LH} \beta, \mathrm{GnRH}$ receptor expression was not modulated by treatment with RES.

Long-term treatment with E2 showed differential effects on the expression pattern of ERs. Expression of ER $\alpha$ remained unaltered under any treatment (data not shown) whereas ER $\beta$ mRNA expression was upregulated following OVX (Fig. 7). Rats that received subcutaneous implants and those fed with the high dose of E2 showed downregulation of ER $\beta$ mRNA to the values of intact rats. The low dose of orally administered E2 diminished ER $\beta$ expression by two-thirds. Administration of RES to the animals did not influence ER $\beta$ mRNA levels.

Treatment with E2 modulated the mRNA expression of AhR (Fig. 8). Upon OVX, AhR mRNA increased to $184 \%$ and $213 \%$ compared with intact rats. In rats which were treated subcutaneously with E2, AhR mRNA expression was attenuated to levels comparable with those of untreated animals (Fig. 8A). Rats that were orally fed with the high dose of E2B showed suppression of AhR mRNA whereas animals that were fed with the low dose showed no significant decrease of OVX-induced AhR mRNA upregulation (Fig. 8B). Rats that were treated with RES showed no modulation of AhR gene expression (Fig. 8C).

\section{Discussion}

The results from our study revealed five important findings. (1) RES binds with low affinity to both ERs and with a 10-fold lower affinity to ER $\alpha$ than to ER $\beta$. (2) With a dosage of 5 and $50 \mu \mathrm{g}$ RES/kg bodyweight we achieved serum levels of 1.0 and $8.1 \mu \mathrm{M}$ respectively. (3) Long-term treatment of OVX rats with RES reveals no estrogenic potential on pituitary function in vivo. (4) E2 treatment with implanted capsules exerts stronger effects on $\mathrm{LH}$ and prolactin secretion, as well as on LH $\beta$, LH $\alpha$, GnRH receptor, and ER $\beta$ mRNA regulation compared with orally applied E2B. (5) OVX leads to upregulation of AhR mRNA which is attenuated by E2 treatment.

We have shown that RES binds to ER $\alpha$ with an $\mathrm{IC}_{50}$ of $14.6 \mu \mathrm{M}$ and to $\mathrm{ER} \beta$ with an $\mathrm{IC}_{50}$ of $4 \cdot 8 \mu \mathrm{M}$. Although these values are in the range of previously described reports the data concerning interactions of RES with ERs are conflicting. Two reports describe that, in MCF-7 cells, RES binds to the ER with an $\mathrm{IC}_{50}$ of $10 \mu \mathrm{M}$ or $100 \mu \mathrm{M}$ (Gehm et al. 1997, Ashby et al. 1999). 

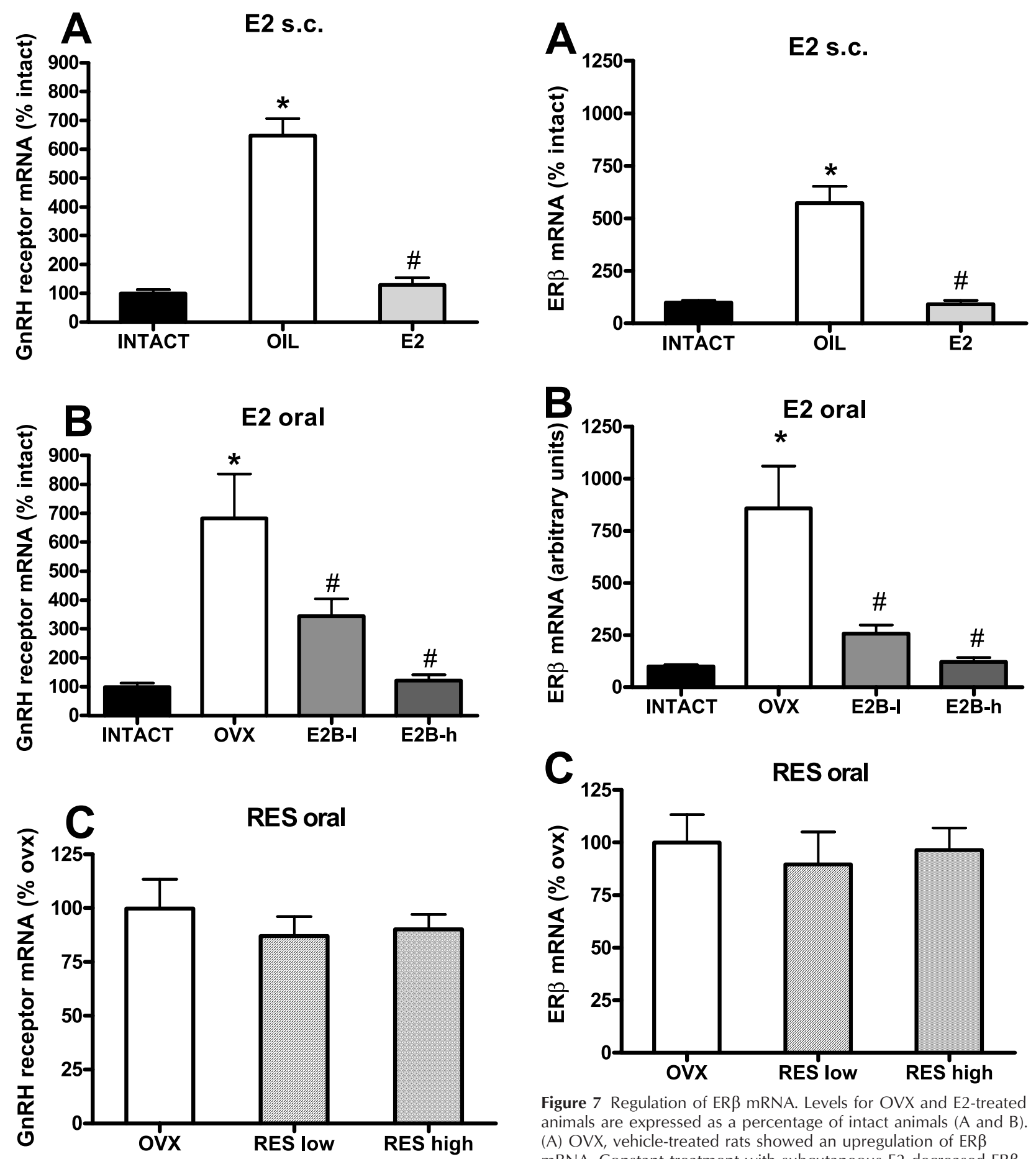

Figure 7 Regulation of ER $\beta$ mRNA. Levels for OVX and E2-treated animals are expressed as a percentage of intact animals (A and B). (A) OVX, vehicle-treated rats showed an upregulation of $E R \beta$ mRNA. Constant treatment with subcutaneous E2 decreased ER $\beta$ mRNA to the levels of control animals. (B) The OVX-induced rise in ER $\beta$ mRNA was dose-dependently attenuated by orally fed E2B. (C) RES-treated animals are shown in relation to the OVX control group. The phytoestrogen did not affect ER $\beta$ mRNA levels. Data are represented as means \pm S.E.M., $n=9-12 .{ }^{*} P<0 \cdot 05$ vs intact; $\# P<0.05$ vs OIL/OVX. Since some of these data are also part of an aging study the data in Fig. 7A are also used in that aging study (Böttner \& Wuttke 2005). no effect on GnRH receptor mRNA levels. Data are represented as means \pm S.E.M., $n=9-12 .{ }^{*} P<0 \cdot 05$ vs intact; $\# P<0.05$ vs OIL/OVX. 

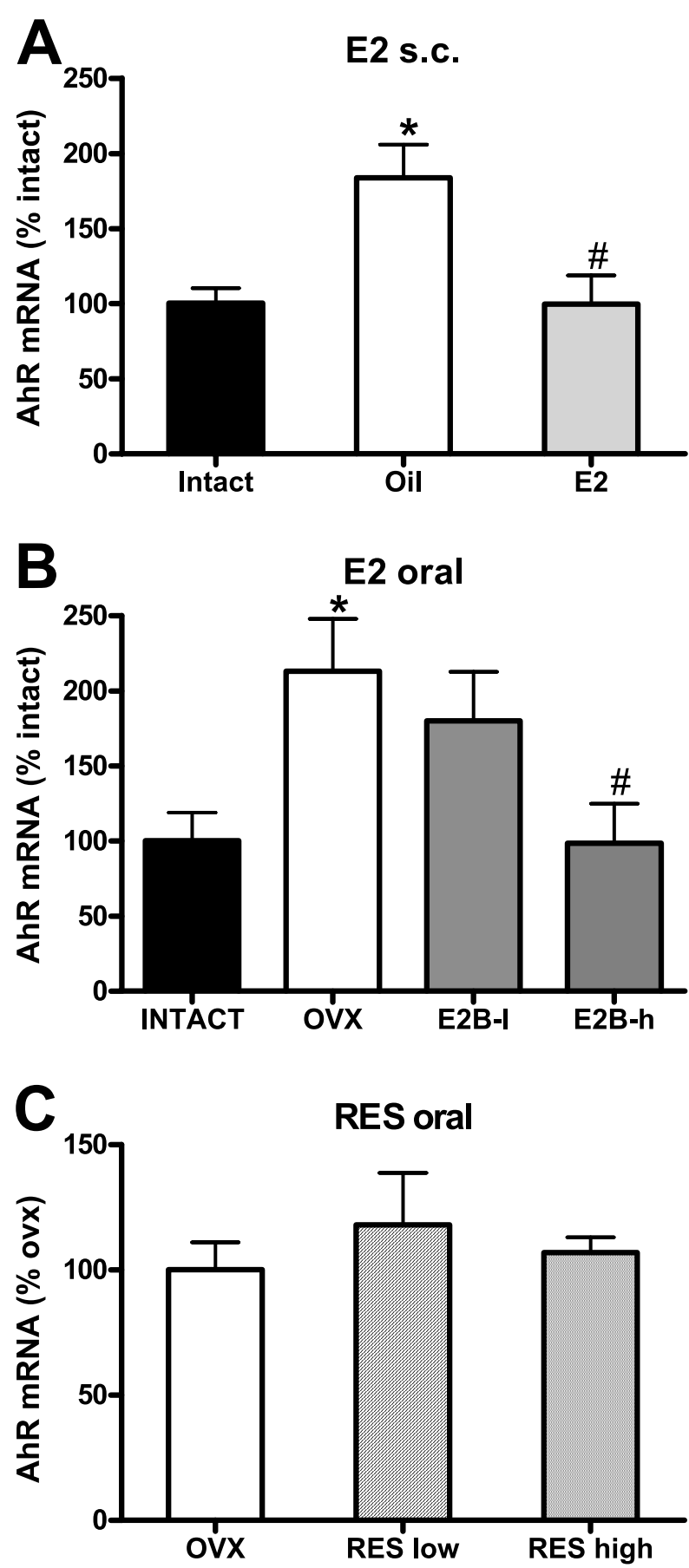

Figure 8 Expression of AhR mRNA. Levels for OVX and E2-treated animals are expressed as a percentage of intact animals (A and B). (A) OVX led to an upregulation of AhR mRNA that was suppressed after subcutaneous E2 application. (B) The high dose of E2B attenuated the rise in AhR following OVX. (C) RES-treated animals are shown in relation to the OVX control group. Orally fed RES did not affect AhR mRNA concentrations. Data are represented as means \pm S.E.M., $n=8-12 .{ }^{*} P<0 \cdot 05$ vs intact; $\# P<0.05$ vs OIL/OVX.
In cell-free systems, Bhat \& Pezzuto (2001) reported no binding of RES to ER $\alpha$ whereas ER $\beta$ was bound with an $\mathrm{IC}_{50}$ of $125 \mu \mathrm{M}$. Other studies demonstrate $\mathrm{IC}_{50}$ values of $58.5 \mu \mathrm{M}$ and $8 \mu \mathrm{M}$ for $\mathrm{ER} \alpha$, and $125 \mu \mathrm{M}$ or $29 \mu \mathrm{M}$ respectively for ER $\beta$ (Bowers et al. 2000, Mueller et al. 2004).

Having demontrated that RES has the capability to bind to ERs, we addressed the question as to whether this effect has any biological significance. Since phytoestrogens have been implicated in the relief of menopausal symptoms including hot flushes (Bagchi et al. 2001) we used the OVX rat as a model to assess the putative estrogenic activity of RES on pituitary function. Upon OVX, LH levels rise due to a lack of negative feedback of E2 on pituitary and hypothalamic centers that control pulsatile GnRH release (Caraty et al. 1989, Shupnik 1996). Subsequently, neurotransmitters involved in generating $\mathrm{GnRH}$ pulses are elevated and cause hot flushes. Exogeneous administration of $\mathrm{E} 2$ leads to suppression of $\mathrm{GnRH}$ release and thereby LH secretion and cessation of vasomotor symptoms. To address the question as to whether RES might be effective in the treatment of hot flushes, we monitored LH secretion in OVX rats that were fed with 5 or $50 \mathrm{mg}$ RES $/ \mathrm{kg}$ bodyweight. However, we could not detect any suppression of LH serum levels, or of any downregulation of $\mathrm{LH} \beta$ and $\mathrm{LH} \alpha$ mRNAs. Similarly, RES was ineffective in reversing the OVX-induced inhibition of prolactin release. These findings are in contrast to the in vitro effects of RES on the pituitary cell line PR1 (Stahl et al. 1998). Stahl et al. (1998) demonstrated that at a concentration of $10^{-6} \mathrm{M}$, RES exerted estrogenic activities with regard to the regulation of prolactin secretion and mRNA synthesis.

The apparent discrepancy between the data derived from an in vitro study and results obtained in vivo might in part be explained by the different doses used in both reports. At $10^{-6} \mathrm{M}$, Stahl et al. (1998) only detected a slight increase in thymidine incorporation and at this concentration the maximal stimulation of prolactin secretion was also observed. In our study, we determined serum levels of total RES of $1 \cdot 0$ and $8 \cdot 1 \mu \mathrm{M}$. Taking into consideration that this value includes unconjugated, glucuronidated, and sulfated RES, the actual amount of free and thus biologically active proportion of RES might be lower than the values denoted above. This assumption is supported by a report describing that, in serum samples of mice fed with RES, glucorinidation and sulfatation of RES occurs (Yu et al. 2002). Given the low affinity of RES to ER $\alpha$, it appears reasonable that our serum levels of active RES might not have been sufficient to activate ER $\alpha$-mediated gene transcription.

Our in vivo observations showing no effects of RES on pituitary function are in agreement with previous reports investigating potential estrogenic effects of RES in rats. The stilbene derivative had only minimal in vivo effects in a study addressing its actions in growing rats (Turner et al. 1999). Another report also failed to detect reproducible 
activity of RES in an immature rat uterotrophic assay (Ashby et al. 1999).

Another possibility for RES to negatively interact with E2 signalling is via the AhR. RES has been shown to bind to the AhR (Casper et al. 1999) and activation of this receptor may result in inhibition of $\mathrm{ER} \alpha$-mediated responses by favoring the proteasome-dependent degradation of ER $\alpha$ and interactions with promoter regions of E2 responsive genes (Safe \& Wormke 2003). Since RES could also activate AhR signaling in the pituitary we determined whether we could detect AhR expression in this organ. Here we have demonstrated for the first time that OVX induces AhR mRNA levels in the pituitary 2-fold compared with intact animals. Chronic treatment with subcutaneous implants of E2 and the pharmacological dose of orally fed E2B attenuated this effect, whereas treatment of OVX rats with RES did not modulate the OVX-induced increase in AhR mRNA levels.

In addition, we assessed the effect of subcutaneous and oral long-term E2 treatment in our animals. To this end, we implemented a paradigm of subcutaneous constant E2 treatment that was designed to mimic constant delivery of E2 via transdermal patches. The other group of rats was fed with two doses of E2B to mimic the oral ingestion of E2 via a pill. These models were used to study the effect of the route of hormone delivery on pituitary function as assessed by LH and prolactin secretion as well as by regulation of $\mathrm{LH} \alpha, \mathrm{LH} \beta, \mathrm{GnRH}$ receptor, and $\operatorname{ER} \beta$ gene transcription. As expected, mean plasma LH concentrations were greatly elevated after 3 months of OVX. Subcutaneous treatment with E2 suppressed LH secretion to levels comparable with those observed in intact animals. In contrast, animals that were orally fed with the low dose of E2 exhibited only partial repression of LH secretion, whereas animals fed with the pharmacological dose showed suppression to levels observed in intact animals.

$\mathrm{LH}$ comprises two subunits including an $\alpha$-subunit common to LH, follicle-stimulating hormone, and thyroid-stimulating hormone, as well as the unique $\mathrm{LH} \beta$ subunit. Changes in LH mRNA expression result from transcriptional regulation of these separate subunits that have individual sensitivity to E2. In accordance with the literature, castration of female rats resulted in increased levels of both subunit mRNAs (Gharib et al. 1986, Papavasiliou et al. 1986). We observed the LHß subunit mRNA was most strikingly regulated with post-OVX values that were 15 -fold higher than in intact animals; $\alpha$-subunit mRNA expression was stimulated to a lesser extent (5-fold). Treatment with E2 decreased the LH $\beta$ values in animals that were subcutaneously treated to $89 \%$ of intact animals. Animals fed with E2B showed, with the low dose, a partial decrease to $700 \%$ of intact animals, rats fed with the high dose exhibited values similar to those observed in intact animals. Similar results were observed concerning the regulation of the $\alpha$-subunit and $\mathrm{GnRH}$ receptor mRNA, demonstrating that constant treatment with implants containing E2 showed more striking effects on the regulation of pituitary gene transcription than orally applied E2B.

Following OVX, prolactin levels were strongly suppressed. In response to chronic, subcutaneous treatment with E2, prolactin levels rose to values above those observed in intact animals. These findings are in good agreement with previous studies demonstrating that E2 stimulates prolactin secretion in rats by counteracting the effect of dopamine (Chen et al. 1970, Raymond et al. 1978). Furthermore, it is known that E2 modulates prolactin secretion from pituitary lactotrophs in a receptor-dependent fashion (Day et al. 1990, Seyfred \& Gorski 1990). Surprisingly, rats that were orally fed with E2 only showed a tendency to elevated prolactin levels compared with OVX animals but this did not turn out to be significant. These data indicate that not only the doses of hormone but also the route of administration has an influence on the modulation of prolactin secretion. Several studies carried out in postmenopausal women have reported conflicting results regarding the effect of estrogen on prolactin secretion. Our results are consistent with reports showing that estrogens induce prolactin synthesis and raise serum prolactin levels in humans (Frantz et al. 1972, Yen et al. 1974). However, Alvarez-Tutor et al. (1999) described a persistent increase of prolactin levels after oral etinyl-E2 treatment. Other studies observed no alterations in prolactin levels after transdermal estrogen treatment (Saucedo et al. 2002) or a consistent decrease after oral as well as transdermal treatment (Castelo-Branco et al. 1993).

Taken together, the results from our study have demonstrated that subcutaneous treatment with E2 is more efficient in influencing pituitary parameters than orally administered E2B. Furthermore, the lack of estrogenic activity of RES in our studies questions the effectiveness of this phytoestrogen in resolving postmenopausal discomforts including hot flushes.

\section{Acknowledgements}

We thank Maria Metten and Annette Witt for excellent technical support. This work was funded by EURISKED - EVK1-CT-2002-00128 and CASCADE-Fod-CT2004-506319. There is no conflict of interest that would prejudice the impartiality of this scientific work.

\section{References}

Alvarez-Tutor E, Forga LL, Rodriguez-Erdozain R, Goni-Iriarte MJ, Mendendez-Torre E \& Alvarez-Tutor J 1999 Persistent increase of PRL after oral contraceptive treatment. Alterations in dopaminergic regulation as possible etiology. Archives in Gynecology and Obstetics $26345-50$. 
Anderson JJ \& Garner SC 1998 Phytoestrogens and bone. Baillieres Clinical Endocrinology and Metabolism 12 543-557.

Ashby J, Tinwell H, Pennie W, Brooks AN, Lefevre PA, Beresford N \& Sumpter JP 1999 Partial and weak oestrogenicity of the red wine constituent resveratrol: consideration of its superagonist activity in MCF-7 cells and its suggested cardiovascular protective effects. Journal of Applied Toxicology 19 39-45.

Bagchi D, Das DK, Tosaki A, Bagchi M \& Kothari SC 2001 Benefits of resveratrol in women's health. Drugs under Experimental and Clinical Research 27 233-248.

Beral V 2003 Breast cancer and hormone-replacement therapy in the Million Women Study. Lancet 362 419-427.

Bhat KP \& Pezzuto JM 2001 Resveratrol exhibits cytostatic and antiestrogenic properties with human endometrial adenocarcinoma (Ishikawa) cells. Cancer Research 61 6137-6144.

Bhat KP \& Pezzuto JM 2002 Cancer chemopreventive activity of resveratrol. Annals of the New York Academy of Science 957 210-229.

Bhat KP, Lantvit D, Christov K, Mehta RG, Moon RC \& Pezzuto JM 2001 Estrogenic and antiestrogenic properties of resveratrol in mammary tumor models. Cancer Research 61 7456-7463.

Böttner M WW 2005 Chronic treatment with low doses of estradiol affects pituitary and thyroid function in young and middle-aged ovariectomized rats. Biogerontology 6 261-269.

Böttner M \& Wuttke W 2005 Chronic treatment with low doses of estradiol affects pituitary and thyroid function in young and middle-aged ovariectomized rats. Biogerontology 6 261-269.

Bowers JL, Tyulmenkov VV, Jernigan SC \& Klinge CM 2000 Resveratrol acts as a mixed agonist/antagonist for estrogen receptors alpha and beta. Endocrinology 141 3657-3667.

Burger H 2003 Hormone replacement therapy in the post-Women's Health Initiative era. Report of a meeting held in Funchal, Madeira, February 24-25, 2003. Climacteric 6 (Suppl 1) 11-36.

Cadenas S \& Barja G 1999 Resveratrol, melatonin, vitamin E, and PBN protect against renal oxidative DNA damage induced by the kidney carcinogen KBrO3. Free Radical Biology and Medicine 26 1531-1537.

Caraty A, Locatelli A \& Martin GB 1989 Biphasic response in the secretion of gonadotrophin-releasing hormone in ovariectomized ewes injected with oestradiol. Journal of Endocrinology 123 375-382.

Casper RF, Quesne M, Rogers IM, Shirota T, Jolivet A, Milgrom E \& Savouret JF 1999 Resveratrol has antagonist activity on the aryl hydrocarbon receptor: implications for prevention of dioxin toxicity. Molecular Pharmacology 56 784-790.

Castelo-Branco C, Martinez de Osaba MJ, Vanrezc JA, Fortuny A \& Gonzalez-Merlo J 1993 Effects of oophorectomy and hormone replacement therapy on pituitary-gonadal function. Maturitas 17 101-111.

Chen CL, Amenomori Y, Lu KH, Voogt JL \& Meites J 1970 Serum prolactin levels in rats with pituitary transplants or hypothalamic lesions. Neuroendocrinology 6 220-227.

Chiechi LM 1999 Dietary phytoestrogens in the prevention of long-term postmenopausal diseases. International Journal of Gynaecology and Obstetics 67 39-40.

Chiechi LM, Lobascio A, Grillo A \& Valerio T 1999 [Phytoestrogen-containing food and prevention of postmenopausal osteoporosis and cardiovascular diseases.] Minerva Ginecologica (Spanish) 51 343-348.

Chin WW, Godine JE, Klein DR, Chang AS, Tan LK \& Habener JF 1983 Nucleotide sequence of the cDNA encoding the precursor of the beta subunit of rat lutropin. PNAS 80 4649-4653.

Day RN, Koike S, Sakai M, Muramatsu M \& Maurer RA 1990 Both Pit-1 and the estrogen receptor are required for estrogen responsiveness of the rat prolactin gene. Molecular Endocrinology 4 1964-1971.

Derry PS 2004 Hormones, menopause, and heart disease: making sense of the Women's Health Initiative. Womens Health Issues $14212-219$.
Donnelly LE, Newton R, Kennedy GE, Fenwick PS, Leung RH, Ito K, Russell RE \& Barnes PJ 2004 Anti-inflammatory effects of resveratrol in lung epithelial cells: molecular mechanisms. American Journal of Physiology: Lung Cell Molecular Physiology 287 L774-L783.

Dubal DB, Kashon ML, Pettigrew LC, Ren JM, Finklestein SP, Rau SW \& Wise PM 1998 Estradiol protects against ischemic injury. Journal of Cerebal Blood Flow and Metabolism 18 1253-1258.

ElAttar TM \& Virji AS 1999 Modulating effect of resveratrol and quercetin on oral cancer cell growth and proliferation. Anticancer Drugs 10 187-193.

Frantz AG, Kleinberg DL \& Noel GL 1972 Studies on prolactin in man. Recent Progress in Hormone Research 28 527-590.

Gehm BD, McAndrews JM, Chien PY \& Jameson JL 1997 Resveratrol, a polyphenolic compound found in grapes and wine, is an agonist for the estrogen receptor. PNAS 94 14138-14143.

Gharib SD, Bowers SM, Need LR \& Chin WW 1986 Regulation of rat luteinizing hormone subunit messenger ribonucleic acids by gonadal steroid hormones. Journal of Clinical Investigation 77 582-589.

Godine JE, Chin WW \& Habener JF 1982 Alpha subunit of rat pituitary glycoprotein hormones. Primary structure of the precursor determined from the nucleotide sequence of cloned cDNAs. Journal of Biological Chemistry 257 8368-8371.

Heid CA, Stevens J, Livak KJ \& Williams PM 1996 Real time quantitative PCR. Genome Research 6 986-994.

Kuiper GG, Carlsson B, Grandien K, Enmark E, Haggblad J, Nilsson S \& Gustafsson JA 1997 Comparison of the ligand binding specificity and transcript tissue distribution of estrogen receptors alpha and beta. Endocrinology 138 863-870.

Lin JK \& Tsai SH 1999 Chemoprevention of cancer and cardiovascular disease by resveratrol. Proceedings of the National Science Council of the Republic of China B 23 99-106.

Lovekamp-Swan T, Jetten AM \& Davis BJ 2003 Dual activation of PPARalpha and PPARgamma by mono-(2-ethylhexyl) phthalate in rat ovarian granulosa cells. Molecular and Cellular Endocrinology 201 133-141.

Mueller SO, Simon S, Chae K, Metzler M \& Korach KS 2004 Phytoestrogens and their human metabolites show distinct agonistic and antagonistic properties on estrogen receptor alpha (ERalpha) and ERbeta in human cells. Toxicological Science 80 14-25.

Papavasiliou SS, Zmeili S, Herbon L, Duncan-Weldon J, Marshall JC \& Landefeld TD 1986 Alpha and luteinizing hormone beta messenger ribonucleic acid (RNA) of male and female rats after castration: quantitation using an optimized RNA dot blot hybridization assay. Endocrinology 119 691-698.

Poland A, Greenlee WF \& Kende AS 1979 Studies on the mechanism of action of the chlorinated dibenzo-p-dioxins and related compounds. Annals of the New York Academy of Science 320 214-230.

Ramsey LA, Ross BS \& Fischer RG 1999 Phytoestrogens and the management of menopause. Advances in Nurse Practice 7 26-30.

Ravnikar V 1990 Physiology and treatment of hot flushes. Obstetics and Gynecology 75 3S-8S; discussion 15S-17S.

Raymond V, Beaulieu M, Labrie F \& Boissier J 1978 Potent antidopaminergic activity of estradiol at the pituitary level on prolactin release. Science $2001173-1175$.

Roth C, Schricker M, Lakomek M, Strege A, Heiden I, Luft H, Munzel U, Wuttke W \& Jarry H 2001 Autoregulation of the gonadotropin-releasing hormone $(\mathrm{GnRH})$ system during puberty: effects of antagonistic versus agonistic GnRH analogs in a female rat model. Journal of Endocrinology 169 361-371.

Safe S \& Wormke M 2003 Inhibitory aryl hydrocarbon receptor-estrogen receptor alpha cross-talk and mechanisms of action. Chemical Research in Toxicology 16 807-816.

Saucedo R, Rico G, Basurto L, Ochoa R \& Zarate A 2002 Transdermal estradiol in menopausal women depresses interleukin-6 without affecting other markers of immune response. Gynecologic and Obstetric Investigation $\mathbf{5 3} 114-117$. 
Seidlova-Wuttke D, Becker T, Christoffel V, Jarry H \& Wuttke W $2003 a$ Silymarin is a selective estrogen receptor beta (ERbeta) agonist and has estrogenic effects in the metaphysis of the femur but no or antiestrogenic effects in the uterus of ovariectomized (ovx) rats. Journal of Steroid Biochemistry and Molecular Biology 86 179-188.

Seidlova-Wuttke D, Hesse O, Jarry H, Christoffel V, Spengler B, Becker T \& Wuttke W $2003 b$ Evidence for selective estrogen receptor modulator activity in a black cohosh (Cimicifuga racemosa) extract: comparison with estradiol-17 beta. European Journal of Endocrinology 149 351-362.

Seyfred MA \& Gorski J 1990 An interaction between the 5' flanking distal and proximal regulatory domains of the rat prolactin gene is required for transcriptional activation by estrogens. Molecular Endocrinology 4 1226-1234.

Shupnik MA 1996 Gonadotropin gene modulation by steroids and gonadotropin-releasing hormone. Biology of Reproduction 54 279-286.
Stahl S, Chun TY \& Gray WG 1998 Phytoestrogens act as estrogen agonists in an estrogen-responsive pituitary cell line. Toxicology and Applied Pharmacology 152 41-48.

Turner RT, Evans GL, Zhang M, Maran A \& Sibonga JD 1999 Is resveratrol an estrogen agonist in growing rats? Endocrinology $14050-54$.

Yen SS, Ehara Y \& Siler TM 1974 Augmentation of prolactin secretion by estrogen in hypogonadal women. Journal of Clinical Investigation $\mathbf{5 3}$ 652-655.

Yu C, Shin YG, Chow A, Li Y, Kosmeder JW, Lee YS, Hirschelman WH, Pezzuto JM, Mehta RG \& van Breemen RB 2002 Human, rat, and mouse metabolism of resveratrol. Pharmacological Research 19 1907-1914.

Received in final form 13 January 2006 Accepted 23 January 2006 